\title{
UCRL-CONF-214175
}

LAWRENCE LIVERMORE N A T IO N A L LABORATORY
Laser Performance Operations Model (LPOM): A Tool to Automate the Setup and Diagnosis of the National Ignition Facility

M. Shaw, R. House, C. Haynam, W. Williams

July 30,2005

SPIE Optics \& Photonics Conference, 2005

San Diego, CA, United States

July 31, 2005 through August 4, 2005 
This document was prepared as an account of work sponsored by an agency of the United States Government. Neither the United States Government nor the University of California nor any of their employees, makes any warranty, express or implied, or assumes any legal liability or responsibility for the accuracy, completeness, or usefulness of any information, apparatus, product, or process disclosed, or represents that its use would not infringe privately owned rights. Reference herein to any specific commercial product, process, or service by trade name, trademark, manufacturer, or otherwise, does not necessarily constitute or imply its endorsement, recommendation, or favoring by the United States Government or the University of California. The views and opinions of authors expressed herein do not necessarily state or reflect those of the United States Government or the University of California, and shall not be used for advertising or product endorsement purposes. 

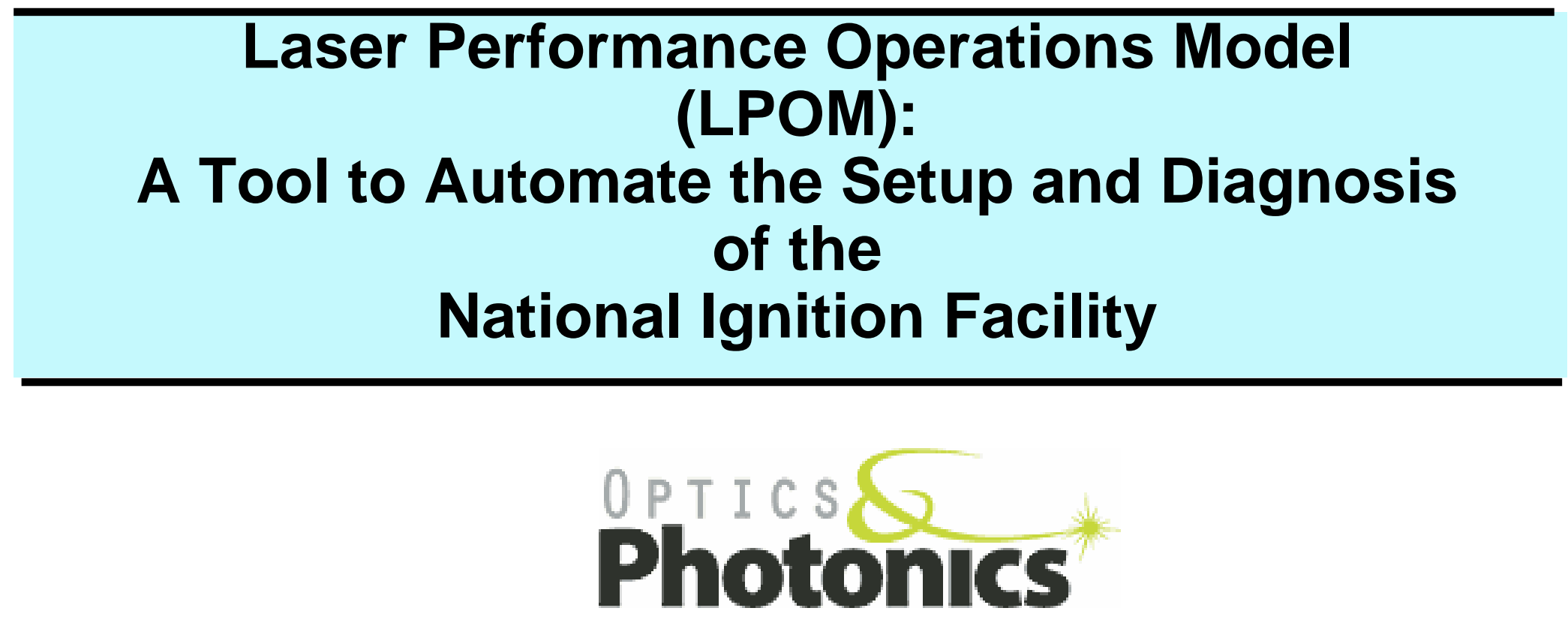

August 3, 2005

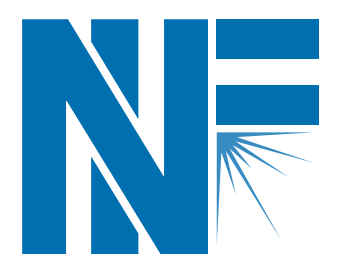

Michael Shaw, Ronald House, Chris Haynam, Wade Williams

Lawrence Livermore National Laboratory, Livermore, CA 94550, USA 
The National Ignition Facility (NIF), currently under construction at the University of California's Lawrence Livermore National Laboratory (LLNL) is a stadium-sized facility containing a 192-beam, $1.8 \mathrm{MJ}, 500-\mathrm{TW}, 351-\mathrm{nm}$ laser system together with a 10-m diameter target chamber with room for nearly 100 experimental diagnostics. When completed, NIF will be the world's largest laser experimental system, providing a national center to study inertial confinement fusion and the physics of matter at extreme energy densities and pressures. The first four beamlines (a quad) have recently been commissioned, and operations on the first bundle (units of eight beamlines) will begin in Summer 2005. A computational system, the Laser Performance Operations Model (LPOM) has been developed and deployed to automate the laser setup process, and accurately predict laser energetics. For each shot on NIF, the LPOM determines the characteristics of the injection laser system required to achieve the desired main laser output, provides parameter checking for equipment protection, determines the required diagnostic setup, and supplies post-shot data analysis and reporting. 


\section{Description of the National Ignition Facility}

- NIF is a stadium-sized facility containing a 192-beam, 1.8-MJ, $500-\mathrm{TW}$, 351-nm laser system

- The beams are grouped in 48, 4-beam quads, which share a common injection laser system

- The target is encased in a 10-meter diameter target chamber with room for nearly 100 experimental diagnostics

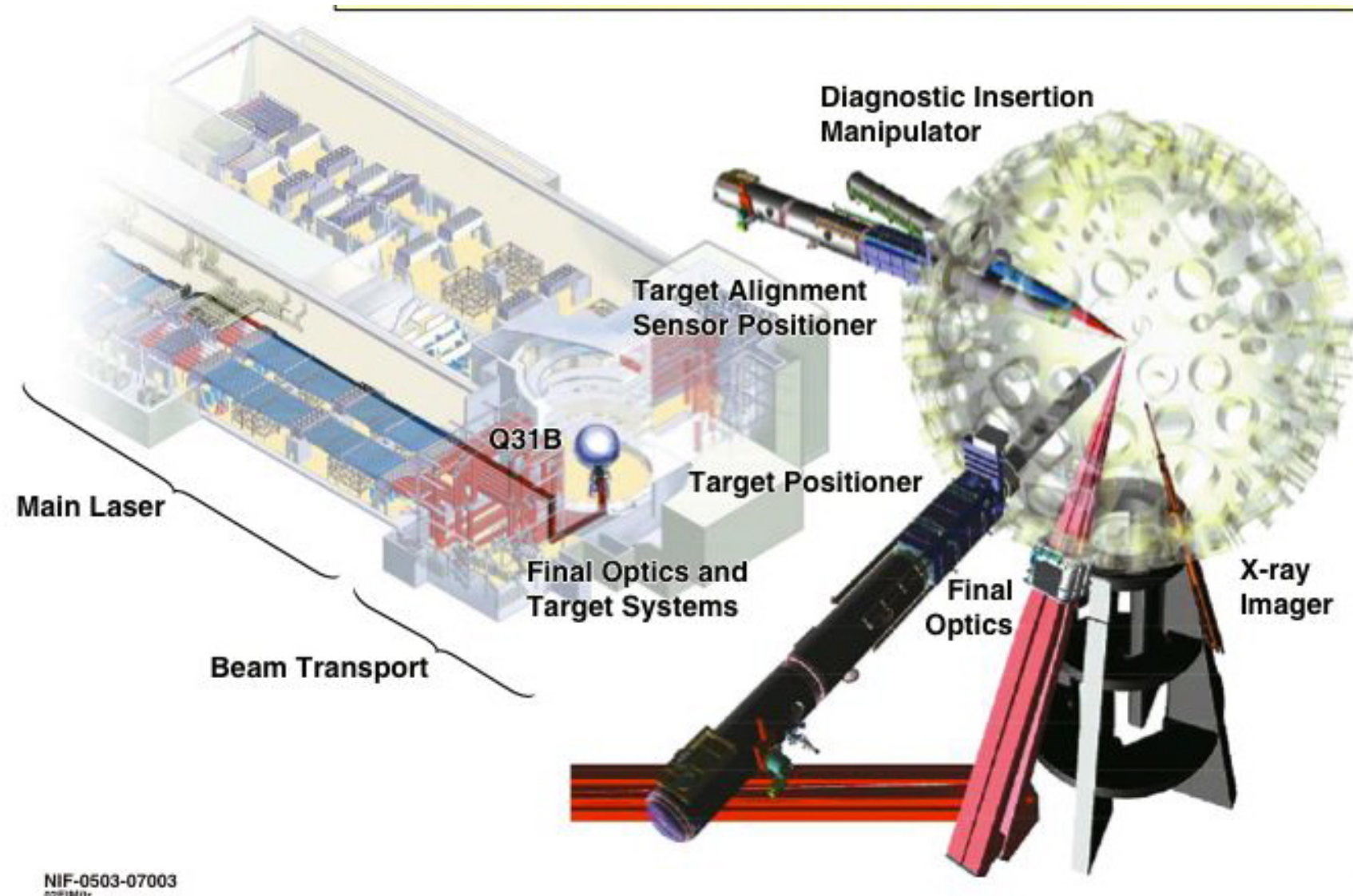




\section{NIF Operations Requires Detailed Laser Energetics Models}

The National Ignition Facility

- NIF operations require precisely specified energy waveforms from 192 beams for a variety of pulse lengths and temporal shapes

- NIF laser pulses are amplified from $1 \mathrm{~nJ}$ up to $20 \mathrm{~kJ}$

- Injected pulses undergo significant pulse distortion due to gain saturation

- The system must accurately control 192 beamlines and 48 injection laser systems that have variations in:

- Beamline-to-beamline optical transmission;

- Beamline-to-beamline amplifier slab configurations (gain);

- Quad-to-quad amplifier pumping

- NIF to be operated at very high energy and power, but with low risk of optical damage

- The Laser Performance Operations Model (LPOM) has been developed to provide this functionality for NIF 


\section{Laser Performance Operations Model (LPOM) Functional Requirements}

- Automate shot setup

- Specifies injection laser energy and temporal shape;

- Predicts laser fluence at all laser diagnostic locations;

- Feedback data to update the laser model

- Assists in equipment protection

- Assures that the predicted fluences and intensities lie within operational limits

- Verifies that injection system is properly configured prior to main laser shot

- Post-shot analysis and archive tool

- Post shot data reports and analysis tools

- Web browser access to processed data provide easy access before, during and after shot operations

LPOM supports shot planning, operations, shot director and NIF users 


\section{LPOM consists of several interacting, functional modules}

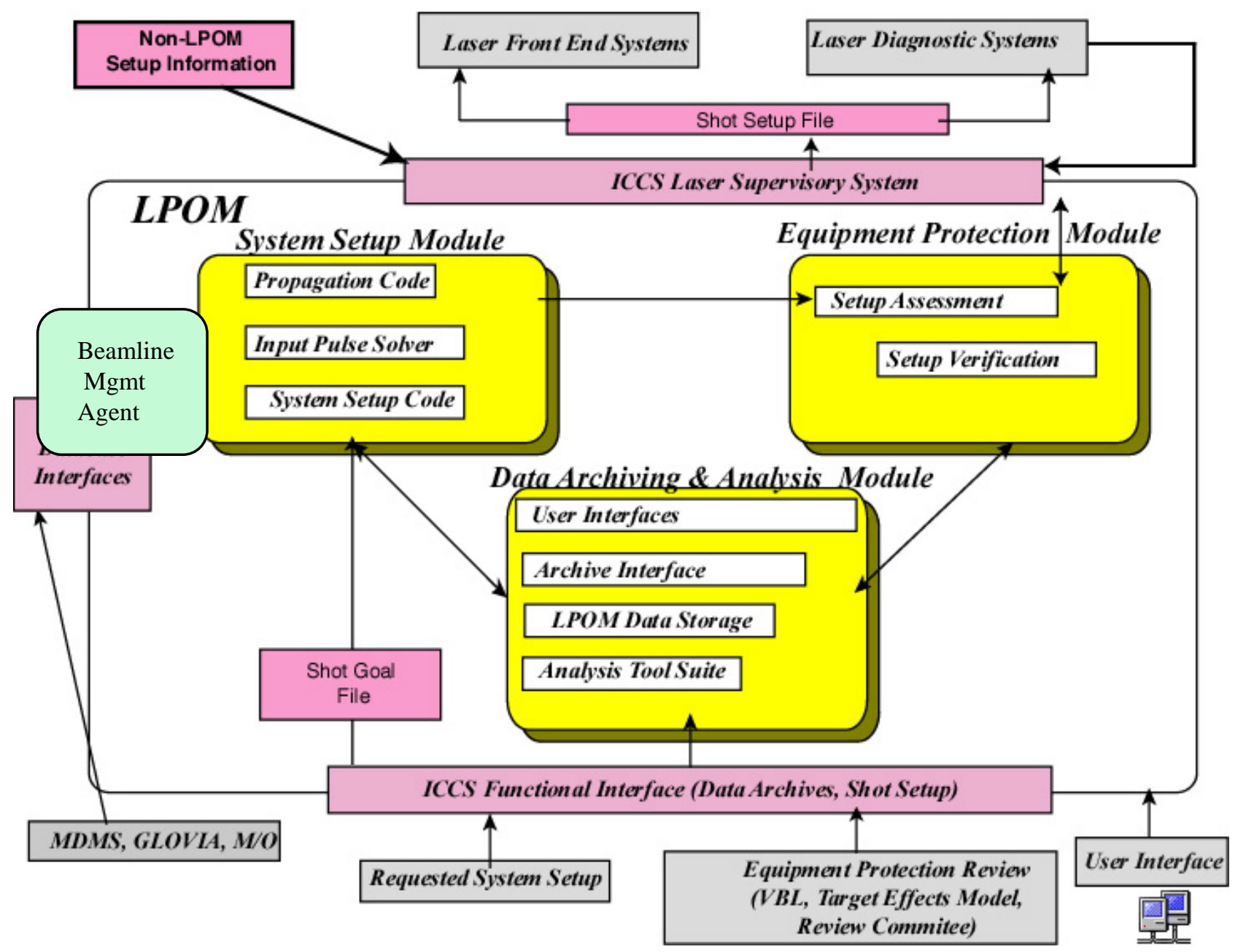




\section{LPOM automates shot setup and uses post shot analysis to maintain an accurate model of NIF}

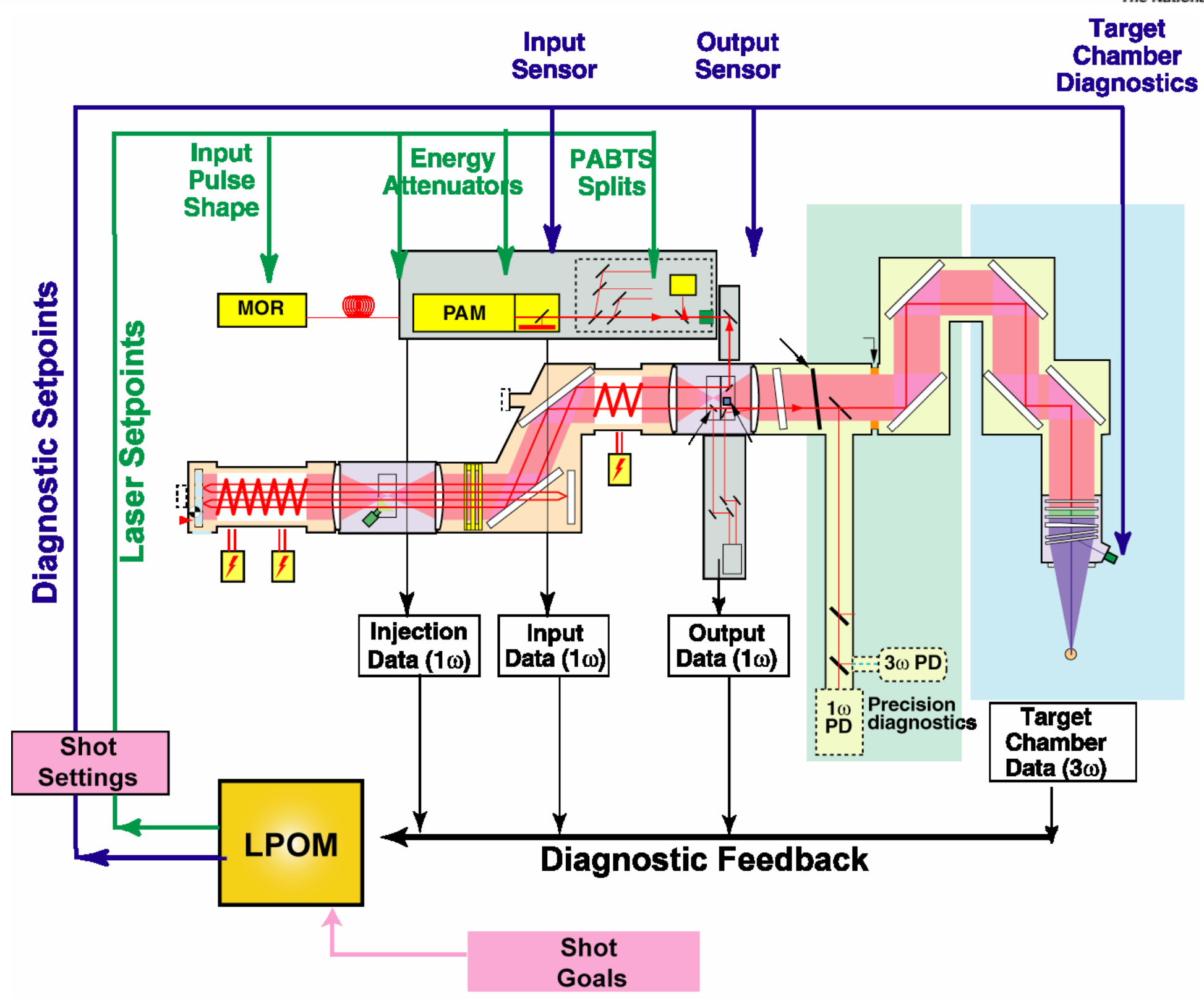




\section{A comprehensive beamline model is essential to accurately describe how NIF works}

The National Ignition Facility

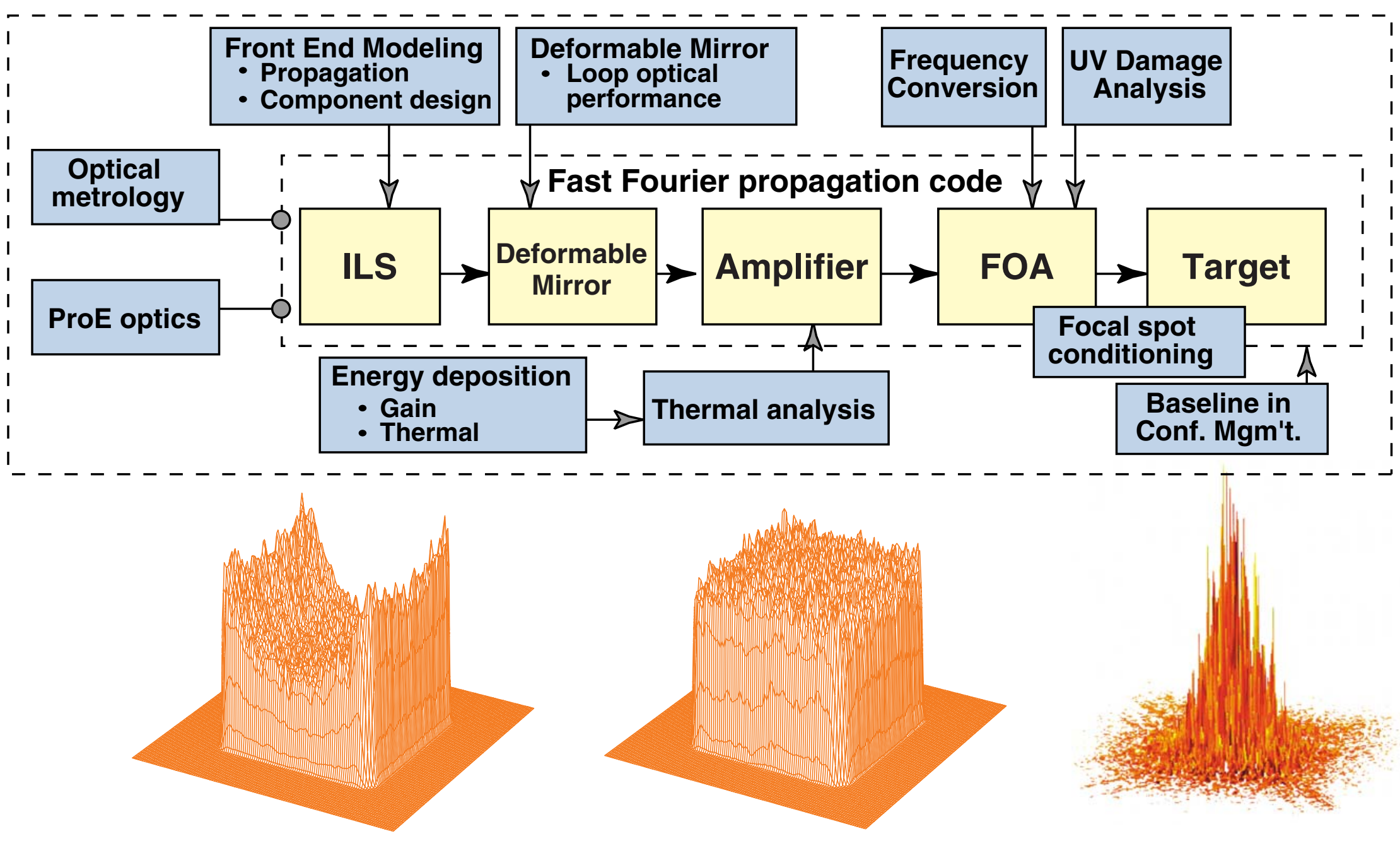




\section{LPOM turns goals into the required shot settings for NIF subsystems}

- LPOM turns high level shot goals into specific shot settings

- Settings communicated to other NIF laser subsystems through

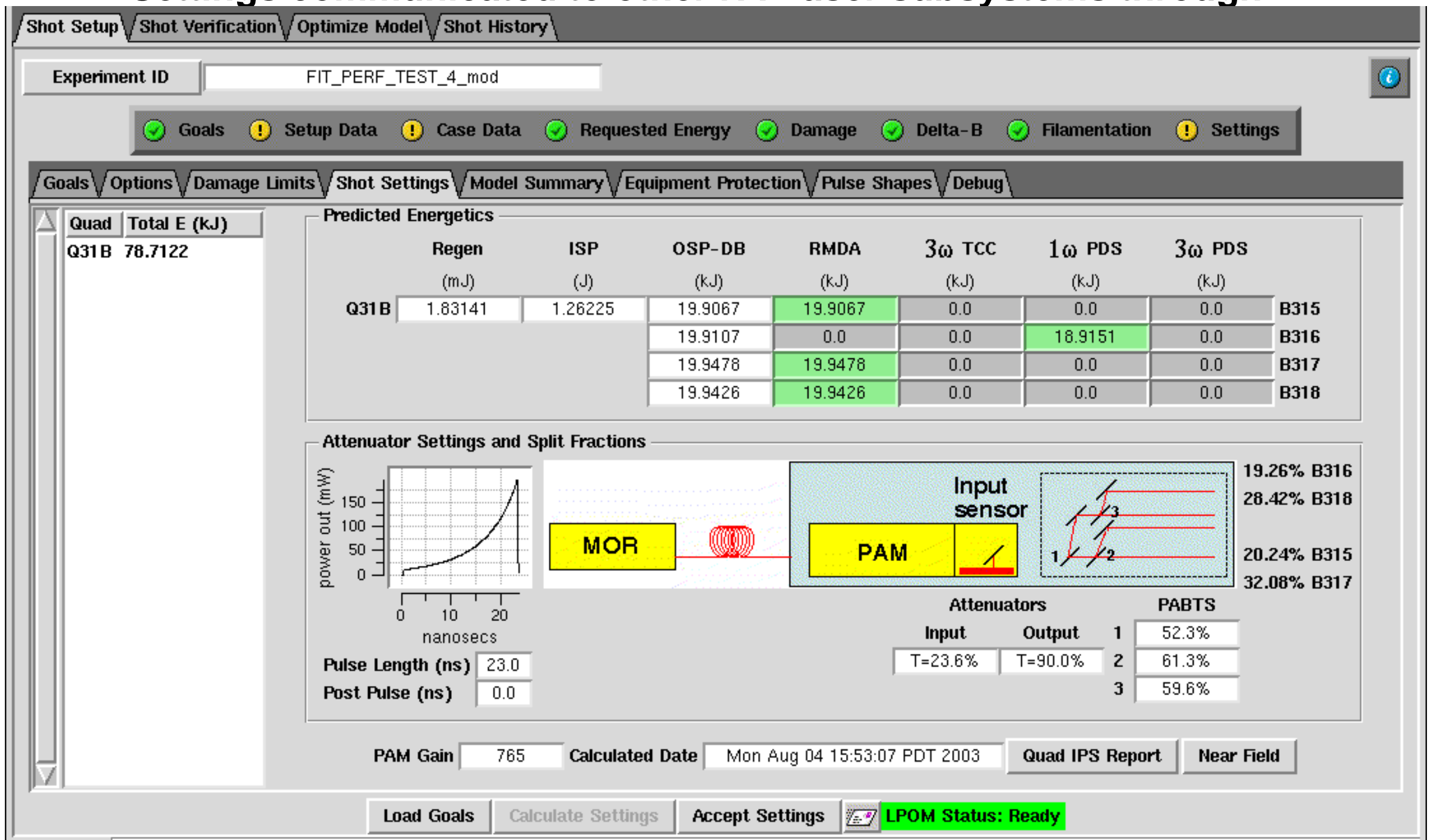




\section{EQUIPMENT PROTECTION}




\section{LPOM plays a critical role in the protection of the NIF laser}

LPOM has three roles in the NIF equipment protection process

- Prior to shot:

- Compares predicted fluences and intensities to optical damage limits

- During the shot cycle:

- Verifies injection laser system produces energy, power and spatial distribution required for a full system shot

- Automatically alerts Shot Director with status of system

- After main laser shot:

- Compares measured values to predicted, providing

- A quick determination the success of a shot; and

- Validation of the LPOM model 


\section{LPOM provides expert groups detailed pre-shot analysis of equipment risk of proposed shots}

The National Ignition Facility

- Results of Shot Setup calculations provide information concerning the risk to critical optical component throughout the NIF system

- Due to level of confidence in LPOM calculations, no shots that exceed damage limits are allowed to be scheduled

\begin{tabular}{|c|c|c|c|c|c|c|c|c|c|c|c|}
\hline & 31B & Maximur & Optic Name & Beamline $\longdiv { L }$ & Legend: & & & & & & \\
\hline Optics Dan & age (Fluena & 7) $99.34 \%$ & PM1 & B318 & sate & & & & & & \\
\hline & tata-B & $1.34 \%$ & Debris Shield & B318 & above thres & & & & & & \\
\hline$\checkmark$ Filamenta & on (ntensity) & $29.46 \%$ & SF4 & B316 & (1]) above conditionir & fivence & & & & & \\
\hline Optic Name & Max Flu & Ave Flu & Damage Flu & Damage Rat & $\begin{array}{ll}\text { atio } & \text { Max Delta-B }\end{array}$ & Beam Area & Tau Eq & Max int & Filament Ratio & fac over damage & \\
\hline Debris Shield & 15.86 & 6.26 & 4.00 & 3.97 & 1.34 & 781.84 & 2.27 & 3.59 & 0.18 & & B318 \\
\hline Tripler & & 5.85 & 4.00 & 3.71 & $0.54 \mathrm{P}$ & 853.11 & 2.27 & 3.35 & 0.17 & 0.97 & B318 \\
\hline FFL & $\begin{array}{l}1.005 \\
1.84\end{array}$ & 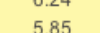 & 400 & 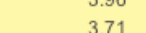 & 105 & 855311 & 227 & 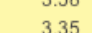 & 0.17 & $\begin{array}{l}0.30 \\
0.97\end{array}$ & $\begin{array}{l}8318 \\
83218\end{array}$ \\
\hline & & & & 0.52 & 0.54 & & 297 & 541 & 0.27 & 000 & B318 \\
\hline Pol on reff & 7.94 & 6.07 & 9.84 & 0.81 & 0.43 & 847.61 & 249 & 247 & 0.12 & 0.00 & B315 \\
\hline & 8.23 & 6.02 & 9.79 & & 0.43 & 853.59 & & 2.68 & 0.13 & 0.00 & B316 \\
\hline & & & & & & 873.52 & & & 0.13 & 0.00 & B317 \\
\hline Pol on refl & 8.07 & 5.91 & 9.75 & 0.83 & 0.42 & 863.47 & 2.43 & 2.72 & 0.14 & 0.00 & B318 \\
\hline LM3 & & & & & & & & 2.45 & & 0.00 & 8315 \\
\hline 徒 & 808 & & 染, & 然 & . & 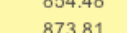 & 年, & 年, & 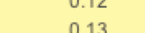 & 然 & 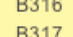 \\
\hline LM3 & 7.82 & 590 & 974 & 0.80 & 042 & 86422 & 242 & 265 & 0.13 & 0.00 & B318 \\
\hline LM2 & 0.11 & 0.06 & 8.94 & 0.01 & 0.00 & 911.76 & 1.89 & 0.05 & 0.00 & 0.00 & B315 \\
\hline LM2 & 0.11 & 0.06 & 8.94 & 0.01 & 0.00 & 916.93 & 1.89 & 0.05 & 0.00 & 0.00 & B316 \\
\hline LM2 & 0.12 & 0.078 & 8.94 & 0.01 & 0.00 & 941.53 & 1.90 & 0.05 & 0.00 & 0.00 & 8317 \\
\hline ectMirt & 0.17 & . & 2177 & . & . & 248 & 104 & . & . & . & . \\
\hline $\begin{array}{l}\text { If)ect Miror } \\
\text { Injirect }\end{array}$ & . & 0.06 & 2172 & 0.01 & 000 & 246 & 184 & 0.07 & 000 & 000 & 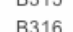 \\
\hline Inject Miror & 0.25 & 0.09 & 21.72 & 0.01 & 0.00 & 2.46 & $\begin{array}{l}1.84 \\
1.84\end{array}$ & 0.12 & 001 & & 年 \\
\hline Inject Mirror & & & 21.72 & 0.01 & 0.00 & 2.49 & 1.84 & 0.09 & 0.00 & 0.00 & B318 \\
\hline PM7 & & & 22.88 & & 0.32 & 859.83 & 2.59 & 5.19 & 0.26 & 0.00 & \\
\hline PM1 & 17.45 & 9.19 & $17.57 \mathrm{Z}$ & 0.99 & 0.26 & 852.87 & 2.80 & 4.67 & 0.23 & 0.00 & B318 \\
\hline $\begin{array}{l}\text { TCW } \\
\text { SF1(nasest) }\end{array}$ & 21.51 & 8.64 & 37.3.36 & 0.58 & 0.54 & 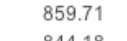 & 2.84 & 5.41 & 0.27 & 0.000 & B318 \\
\hline $\begin{array}{l}\text { SF } \\
\text { SF(pass }\end{array}$ & & & & & & 85.131 & & & & & $\begin{array}{l}{ }_{6}^{3315} \\
{ }_{3016}\end{array}$ \\
\hline pass4) & 913 & 575 & 3281 & 0.28 & 93 & 66 & 239 & 273 & 0.14 & 0.00 & B317 \\
\hline SFI(10ass4) & 9.65 & 5.92 & 32.80 & 0.29 & 0.93 & 857.51 & 2.39 & 2.89 & 0.14 & 0.00 & B318 \\
\hline $\mathrm{SF} 3$ & 12.11 & 9.39 & 37.80 & & 04 & 848.54 & 2.93 & 3.37 & 0.17 & 0.00 & B315 \\
\hline & & & & & & & & & & & 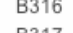 \\
\hline $\mathrm{SF}_{3}$ & 1431 & 90 & 3738 & . & 101 & 86561 & 285 & 3.58 & 018 & 000 & 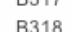 \\
\hline SF4 & 17.54 & 9.39 & 38.43 & 0.46 & 0.20 & 846.19 & 3.05 & 5.45 & 0.27 & 0.00 & B315 \\
\hline
\end{tabular}




\section{LPOM verifies laser system is configured for main system shot}

The National Ignition Facility

- Prior to a full system shot, a shot using only the injection laser system is conducted

- LPOM determines if system is ready for full energy by comparing measurements to predictions

- System readiness communicated to Shot Director within minutes of shot, along with recommended adjustments

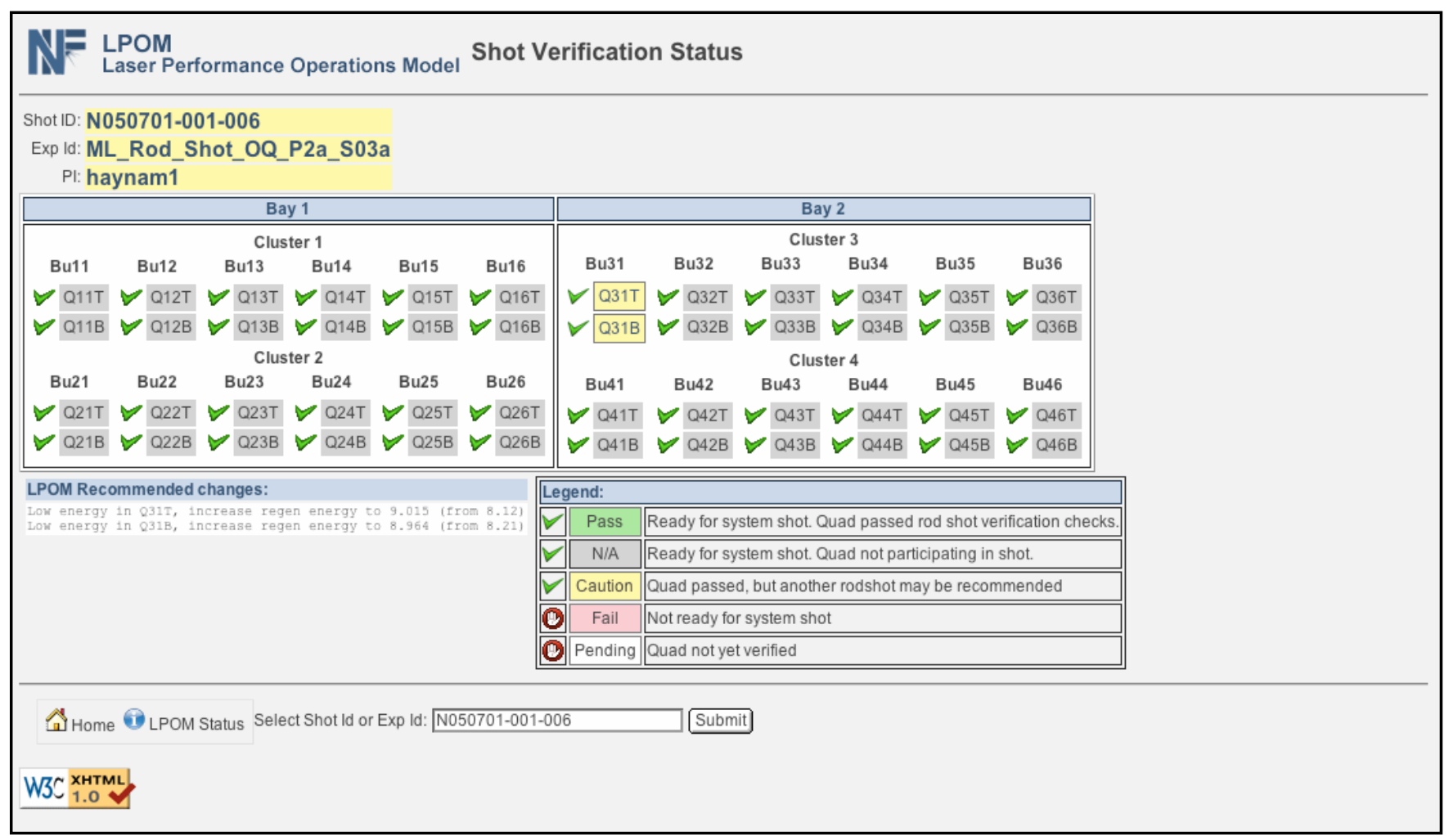




\section{DATA ANALYSIS AND REPORTING}




\section{LPOM presents shot data in a drill down fashion}

- Web-based data reporting tool provides shot data, at various levels of complexity, to NIF community

- Drill-down navigated downward from Shot Status $\Rightarrow$ Shot Metrics $\rightarrow$ Detailed reports for each participating quad

- Parallel computational design assures scalability to full NIF

\begin{tabular}{|l|l|l|l|l|l|l|}
\hline Laser Performance Operations Model Shot Verification Status \\
Shot ID: N050701-001-006 \\
Exp Id: ML_Rod_Shot_OQ_P2a_S03a \\
Pl: haynam1
\end{tabular}




\section{System shot data reporting is accessible immediately to operations and users}

- Second level is a detailed comparison of predicted and measured data

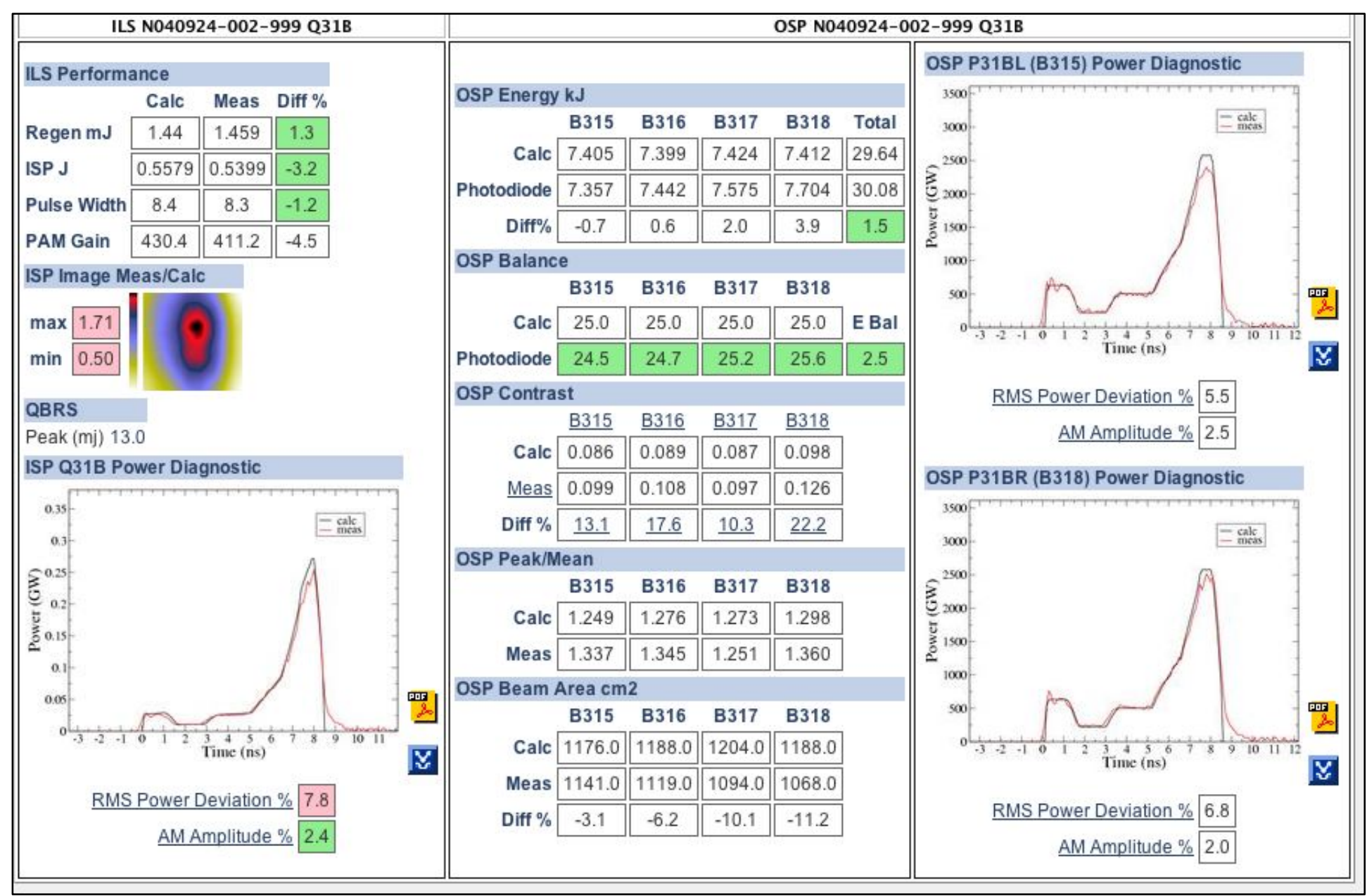




\section{More detailed analysis results can be viewed from results page}

- Hyperlinks from results page allow users to drill down to more detailled analysis reports

- Processed predicted and measured data can be downloaded

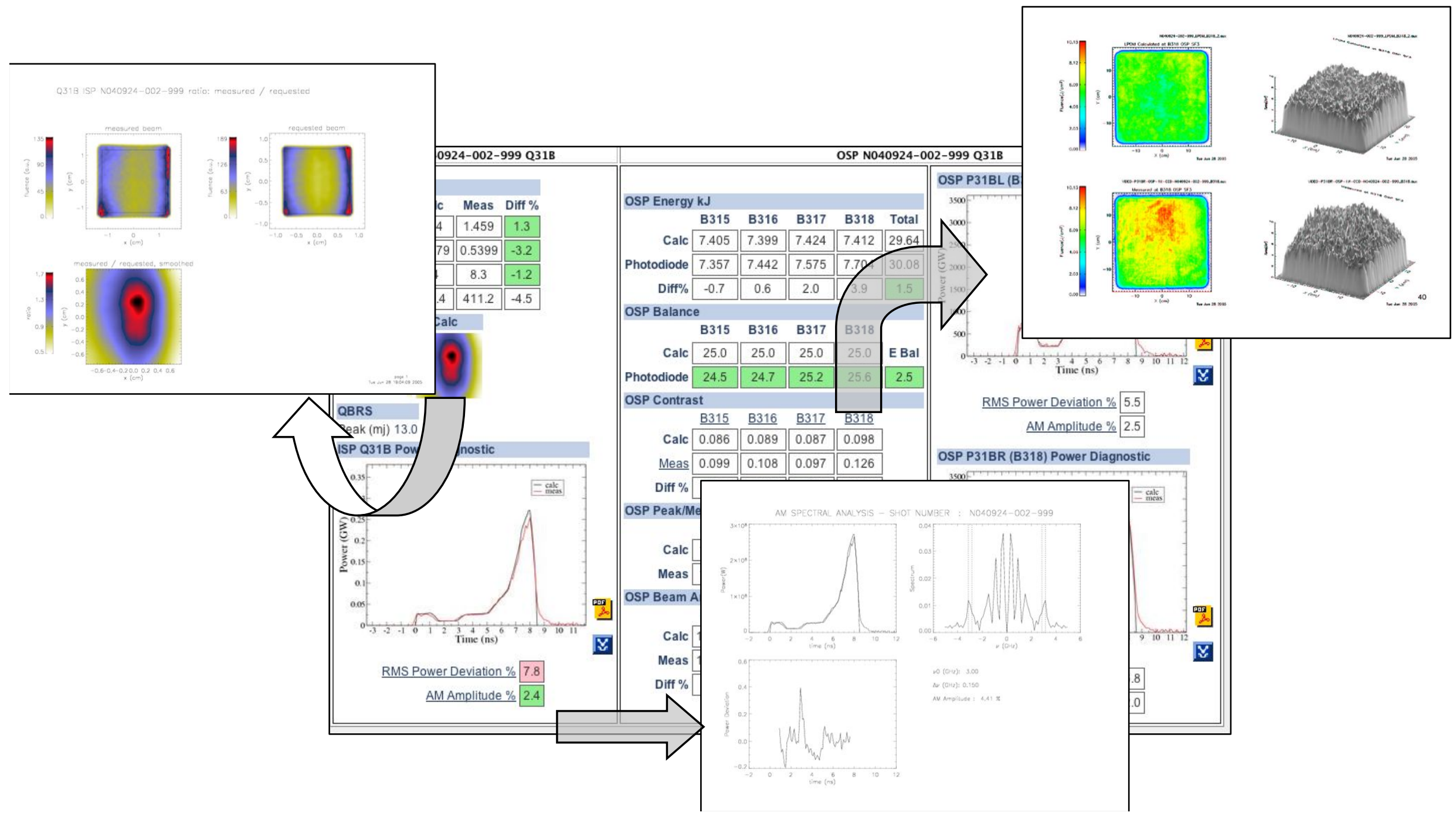




\section{RESULTS}


LPOM has been able to accurately predict energies for each beamline for over a wide operating range

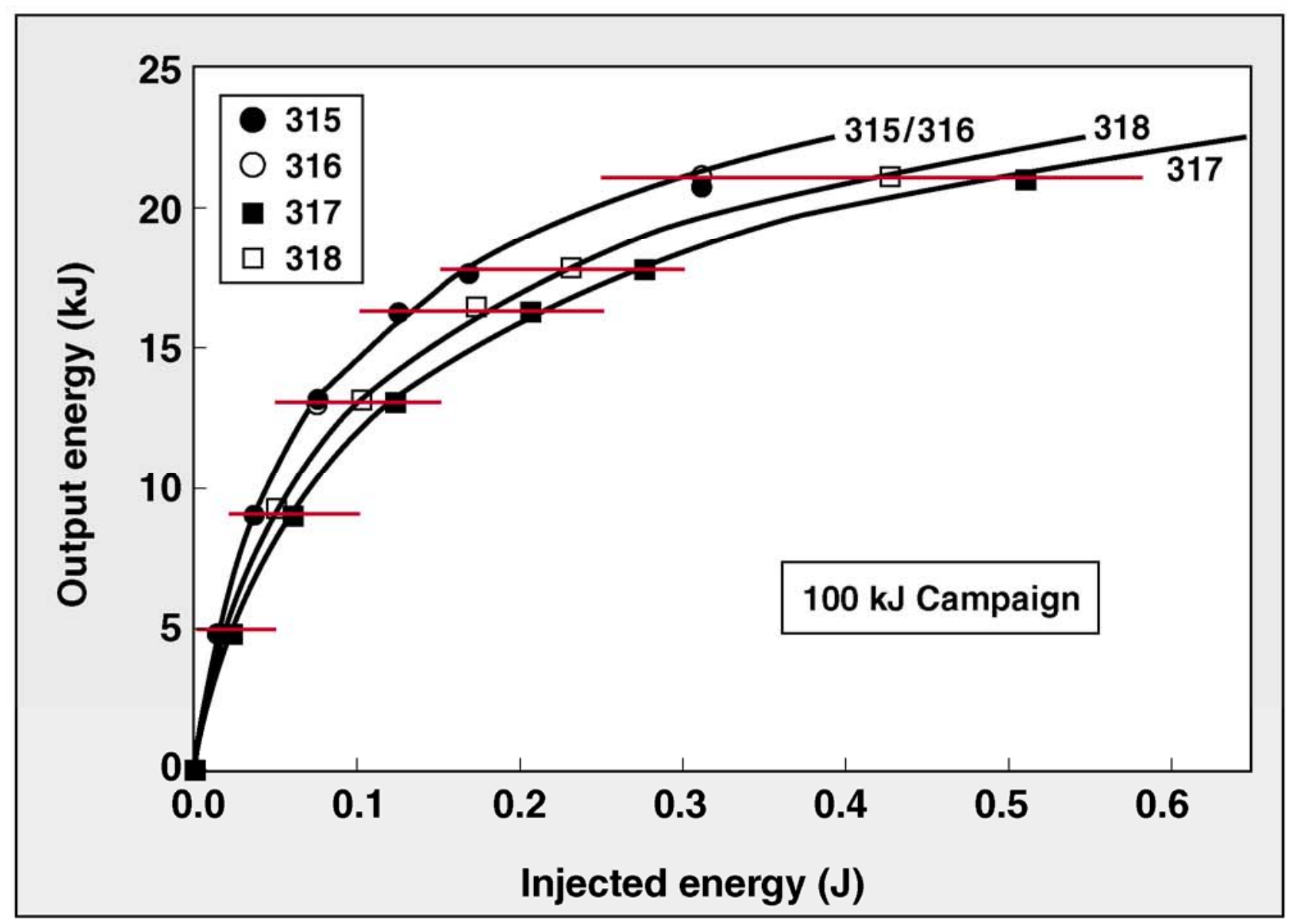

The National lgnition Facility

\begin{tabular}{|c|c|}
\hline \multicolumn{2}{|c|}{ undle 31} \\
\hline 311 & 312 \\
\hline 313 & 314 \\
\hline 315 & 316 \\
\hline 317 & 318 \\
\hline
\end{tabular}

- LPOM calibrated with two low energy shots at beginning of campaign

- Energy balance (within quad) within 1-2\% for all shots 


\section{LPOM accurately models gain saturation of the laser temporal pulse as it propagates}

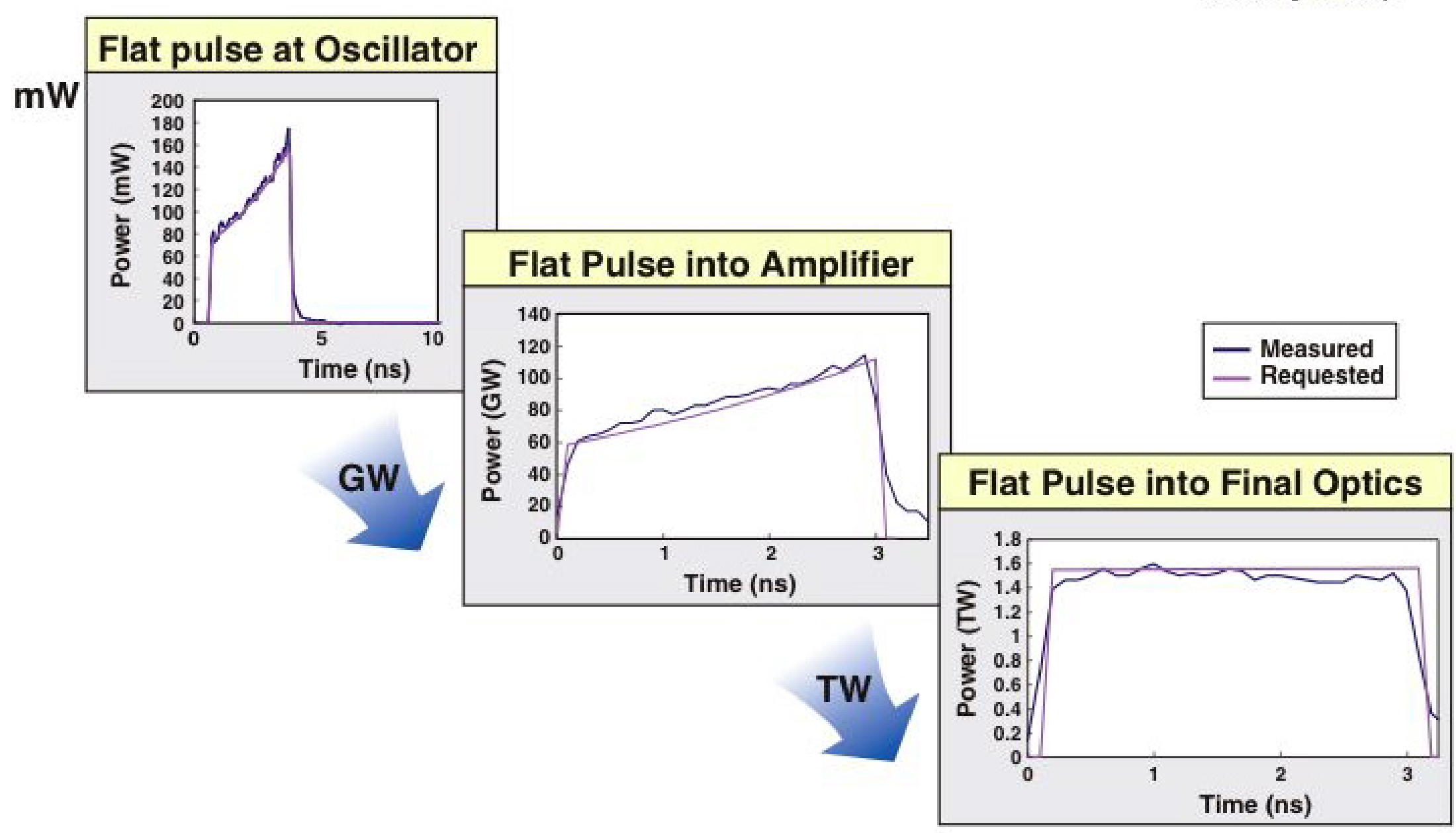

LPOM is the backbone of meeting target irradience requirements 


\section{LPOM has been able to accurately predict pulse shapes for a wide variety of missions}
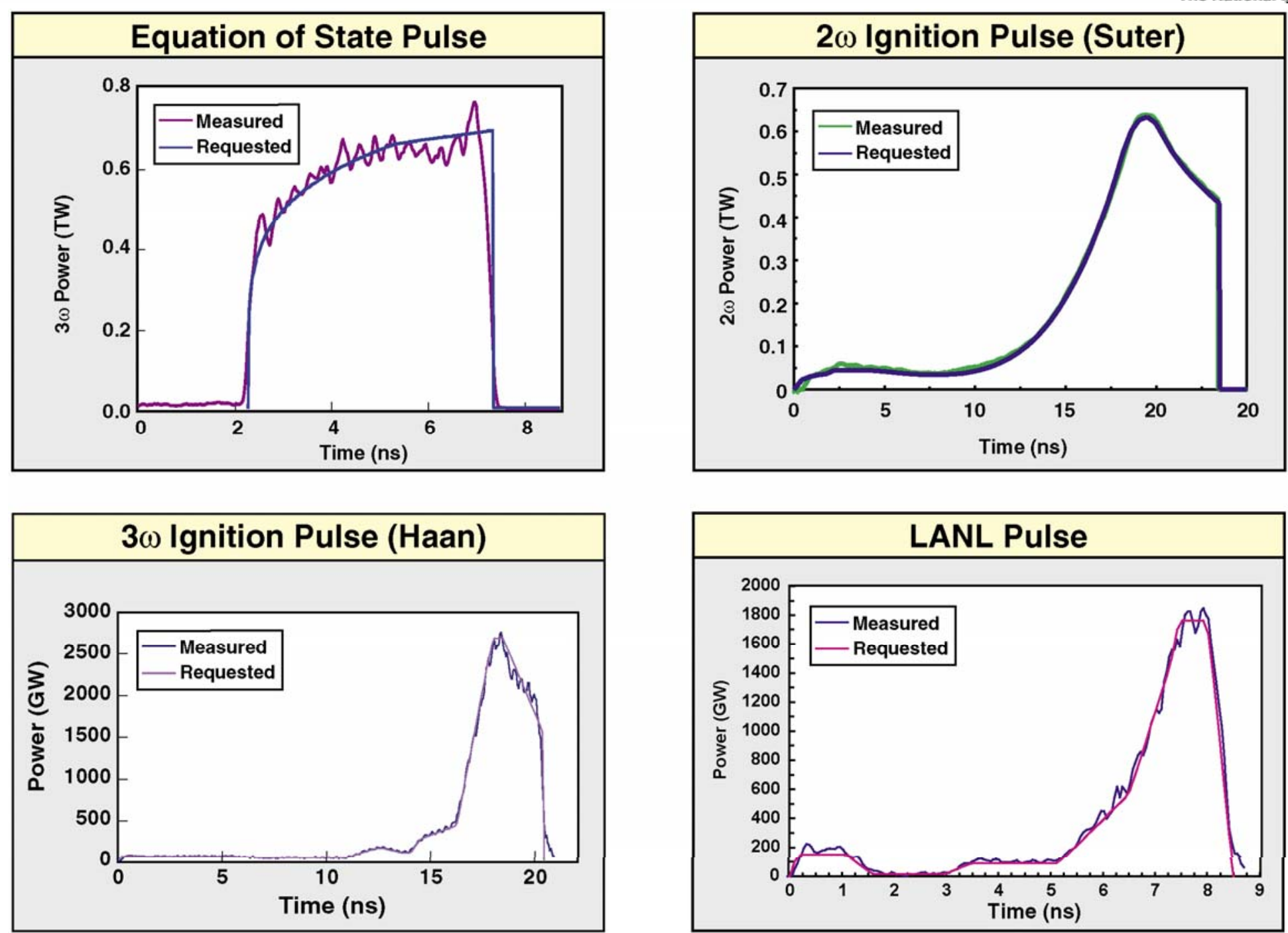

The observed RMS deviation of the Haan pulse is consistent with ignition requirements 


\section{LPOM has helped NIF meet its functional requirements for energy accuracy}

- Power balance requires an 8\% RMS on 3w output energy

- Target campaign shows $<2 \%$ RMS of energy on target
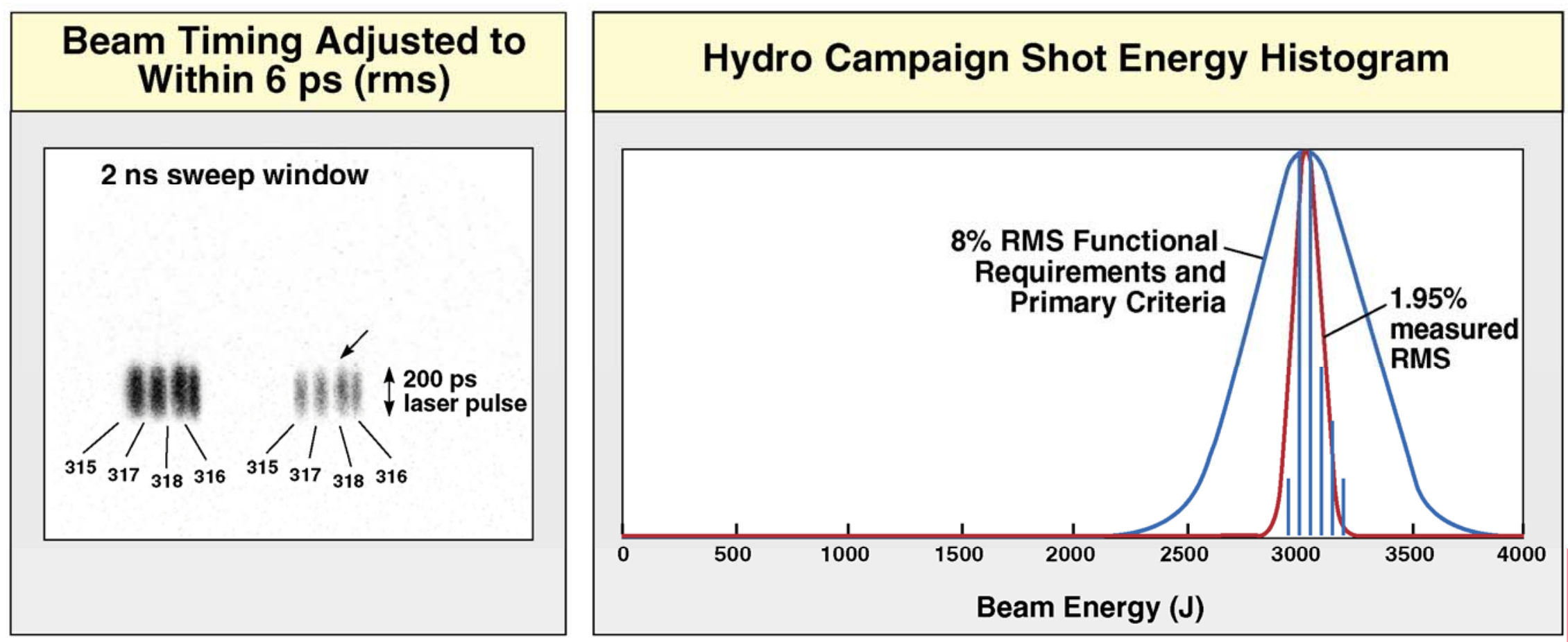

Measured timing and energy stability are consistent with ignition requirements 


\section{Summary}

- LPOM serves a role in automated shot setup, equipment protection and data analysis for NIF

- LPOM has been an invaluable tool in NIF laser commissioning activities

- Accurately set up shot for several laser configurations, and over a wide energy range

- Provide energy balance amongst the quad to within 1-2\%

- Produces output pulse shapes that are flat or match complicated requested shapes

- LPOM provides post-shot data reporting and analysis

- Web-based reporting tool provides data to aid shot operations, shot planning and data analysis

- LPOM has been proven to be scalable and capable of operating in a fully automated fashion 